\title{
Review Article \\ Fuzzy Quality Function Deployment: An Analytical Literature Review
}

\author{
Mohammad Abdolshah ${ }^{1}$ and Mohsen Moradi $^{2}$ \\ ${ }^{1}$ Department of Engineering Faculty, Islamic Azad University, Semnan Branch, P.O. Box 35136-93688, Semnan, Iran \\ ${ }^{2}$ Department of Industrial Engineering, Semnan University, Semnan, Iran
}

Correspondence should be addressed to Mohammad Abdolshah; abdolshah@gmail.com

Received 10 December 2012; Revised 1 April 2013; Accepted 8 April 2013

Academic Editor: Hsin-Hung Wu

Copyright ( 2013 M. Abdolshah and M. Moradi. This is an open access article distributed under the Creative Commons Attribution License, which permits unrestricted use, distribution, and reproduction in any medium, provided the original work is properly cited.

\begin{abstract}
This paper presents an analytical literature review on fuzzy quality function deployment (FQFD) of papers published between 2000 and 2011. In this review, publications were divided into two main groups. First group included publications which proposed some models to develop FQFD. The second one was related to new applications of FQFD models. Next, publications were analyzed and research gaps and future directions were presented. We reached some conclusions including the following. (i) Most of studies were focused on quantitative methods to accomplish phase 1 of QFD or House of Quality (HoQ). The most employed techniques were multicriteria decision making (MCDM) methods. (ii) Although main purpose of using QFD was product development, other factors such as risk and competiveness analysis should be considered in product development process. (iii) A promising approach is using of metaheuristic methods for solving complicated problems of FQFD. (iv) There are a few studies on completing all phases of FQFD.
\end{abstract}

\section{Introduction}

Quality function deployment (QFD) is a customer-driven product development tool to achieve higher customer satisfaction through translating customer needs (CNs) into design requirements (DRs), part characteristics (PCs), and production plans and control [1]. Chan and Wu [2] defined QFD as "a system to assure that customer needs drive product design and production process." QFD is used essentially in order to design product according to customer favorites. A general QFD process consists of 4 phases. First phase, which is called House of Quality (HoQ), is an important stage in deploying QFD process. In this stage, after determining CNs and technical characteristics (TCs), relationships between CNs (Whats) and TCs (Hows) as well as their interdependencies are established and their importance weight is calculated [1]. In second phase TCs are translated to important PCs. Critical parameters of process are established in third stage and finally production requirements are specified (fourth phase) [3].

Most of required data in QFD processes and activities are expressed in natural language. Customers, for example, say their expectations from product by using expressions such as "easy to use," "safe," and "comfortable" which all of them have ambiguity. Computing these ambiguities in a requirement is an important issue [4]. Using tools from fuzzy sets and their concepts, we can approximate linguistic data to a numeric precision [5]. This review, consisting of a bank with more than 70 papers, divided publications in two main groups. First was publications combining FQFD with other methods to develop its efficiency and effectiveness, and latter was publications in new and major applications of FQFD. Each of these two groups was divided into subgroups. In the 2nd section we discuss these two groups, respectively. Discussed papers were analyzed in the fourth section and the literature vacancies were described.

\section{Proposed Models for Developing FQFD}

There are lots of models proposed to develop FQFD. In fact, according to wide aspects of deploying fuzzy QFD, it may be used in combination with many other methods and models. All of these models are common in using fuzzy logic. 


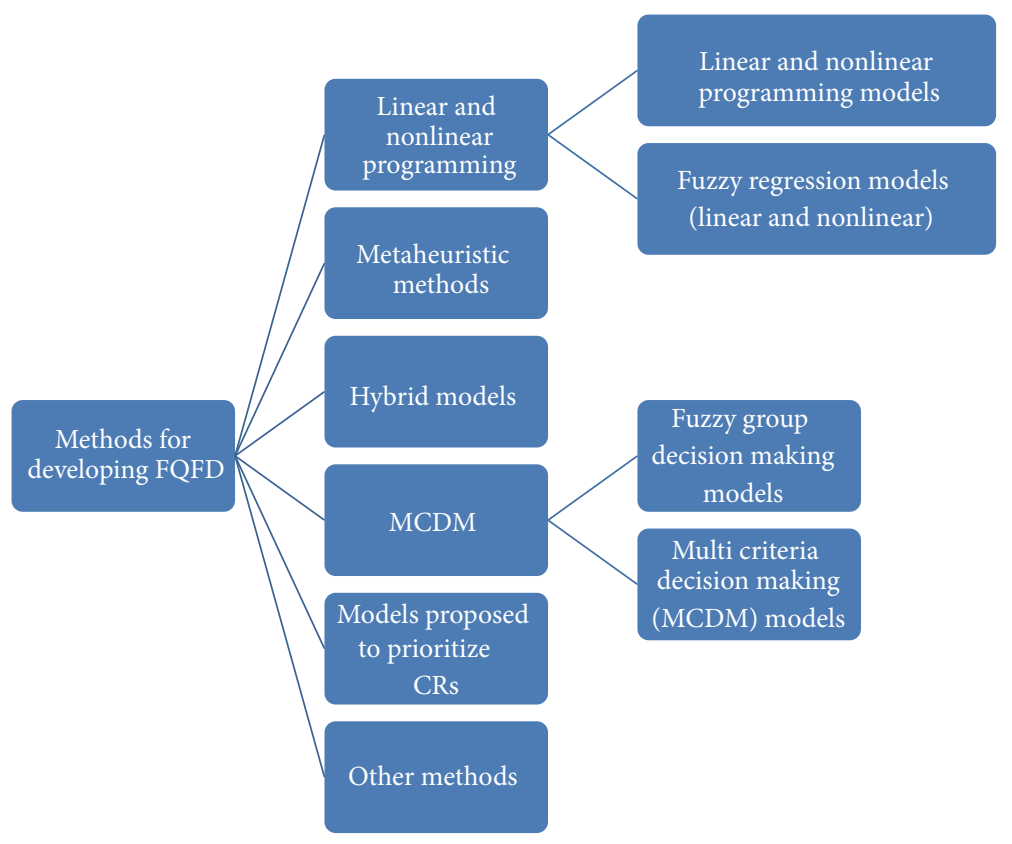

FIGURE 1: Categorizing the models for developing FQFD.

Here, according to the literature, this group is divided into 5 following subgroups to be discussed. Then as shown in Figure 1 these 5 groups can be discussed in 8 different groups.

2.1. Fuzzy Linear and Nonlinear Programming Models. Linear programming methods have been widely used in FQFD. These models are mostly employed to compute fulfillment levels of process parameters (e.g., TCs, PCs) respecting some constraints like budget, technical difficulty, and technology. Followings are some presented models in the literature.

Ko and Chen [6] presented a fuzzy linear programming (FLP) using QFD and fuzzy normal relations evaluation method for new product development (NPD). They used FLP to determine fulfillment levels of engineering characteristics and design requirements to maximize customer satisfaction with respect to company's sources, technical difficulties, and market competition constraints. In this model, in order to identify relationships between CRs and DRs as well as interdependencies within DRs, Wassermann's equation has been used. Also relationships between characteristics were represented by fuzzy number to cope with fuzziness. In that model, percentage increase of costs corresponding to increase of fulfillment levels of each TC was specified and total costs could not be more than a given value. Minimum fulfillment level of each DR was known and fulfillment level of DR couldn't be less.

Luo et al. [7] proposed an optimization method based on FQFD for part selecting. Their model became an integer linear programming model at the end. This model considered CNs as fuzzy numbers and translated them to TCs and finally to PCs. Their final goal was minimizing the differences between CNs and end product. Chen and Ko [1] proposed fuzzy linear programming models to determine the fulfillment levels of PCs and failure modes and effect analyses
(FMEA) for risk analysis. This paper proposed FLP models for determining fulfillment levels of PCs to achieve given levels of DRs to satisfy customers and considered both phases 1 and 2 of NPD. Furthermore, to reduce risk FMEA as a constraint for models in QFD process was introduced. To assure customer satisfaction, this paper considered fulfillment level of $J$ th DR in phase 2 more than or equal to that in phase 1.

Chen and Ko [3], in other study, considered close relationships of 4 phases of QFD by means of end chain concept (MEC) and proposed a set of FLP models to determine contribution level of HOWs in customer satisfaction. They also used FMEA in phases 2 and 3 and risk evaluation in phase 4 , to solve potential risk problem in NPD project. In addition to DRs, in these 4 phases approach PCs, process planning (PP), and process requirements (PRs) have been considered. Solving risk problem in NPD, the authors used fuzzy FMEA as a model constraint for risk evaluation of DRs, PCs, PPs, and PRs in 4 phases. Reliability of models' results depended on reliability of relations between variables and parameters in HoQ, as they said. It was proposed to apply other concepts such as Kano's model instead of MEC in QFD modeling.

In addition to FLP models, one can use fuzzy nonlinear programming (FNLP) models in QFD. Although using these models makes it more difficult, they have a better efficiency in sophisticated problem, because in such problems, relations are often non-linear.

Chen and Ko [6] presented an FNLP model in combination with Kano's model to specify performance levels of DR. They classified DRs in three groups of exciting, functional, and basic using Kano's model. This FNLP was based on FLP model of Chen and Weng (2003). They illustrated with an example that their model was better than corresponding NLP model. Sener and Karsak [8] proposed a hybrid model discussed in Sections 2.2-2.8. 
2.2. Multicriteria Decision Making (MCDM) Models. It can be claimed that among quantitative models used in FQFD, MCDM models are the most used ones. These models in QFD matrixes (often HoQ) are applied in determining importance of parameters.

Kim et al. [9] used MCDM models for calculating target values of TCs as an optimization problem. Target function was finding target value levels of TCs in such a way that customer satisfaction became maximized for target function values.

Kwong and Bay [10] employed fuzzy analytical hierarchy process (FAHP) to weight customer needs. They proposed a fuzzy model for weighting CNs based on fuzzy measurements and traditional AHP. They used triangular fuzzy numbers (TFNs). Two advantages of their model was (1) using fuzzy numbers to deal with ambiguous nature of human judgments and (2) adoption of fuzzy numbers allowed designing team to have freedom of estimation regarding overall goal of customer satisfaction. These estimations could be optimistic or pessimistic.

Erol and Ferrell [11] proposed a method to select among finite alternatives when there are more than one object and data are both quantitative and qualitative. FQFD was used to convert qualitative data to quantitative ones; then this data was combined with other quantitative one to construct multiobjective mathematical model. A modified version of preemptive goal programming was used to solve the model and some solutions close to ideal solution were provided for decision makers to make final decision.

Büyüközkan et al. [12] employed fuzzy analytical network process (FANP) to determine DR weights. They used TFNs in their model. Although FANP proposed in this paper has more calculations than other methods such as FAHP and is more time consuming, results are more precise and, considering long-term competiveness, it is more useful for companies.

Kahraman et al. [5] purposed a fuzzy optimization model for specifying product's technical requirement which should be considered during design process in QFD. Considering interdependencies, target function's coefficient were calculated using FANP. Doing the same with FAHP, they compared results of both methods. Although results were close because of relations within TCs, apparently, FANP had better credibility.

Chen and Weng [13] presented an approach for evaluating of TCs in FQFD using goal programming models. They employed fuzzy goal programming to identify fulfillment levels of DRs according to constraints such as cost, customer satisfaction, and technical difficulties. Coefficients of goal programming were fuzzy to reflect ambiguity in linguistic data. This model also considered business competiveness in determining minimum fulfillment level of DRs. This model used $\alpha$-Cuts to determine membership function of fuzzy goals and fulfillment levels of DRs.

Gunasekaran et al. [14] purposed an MCDM method using Monte Carlo simulation and FQFD for optimization of supply chain management (SCM). Here, customer needs were simulated by FQFD, Monte Carlo simulation, and a multiobjective model for optimizing customer preferences.
By presenting some novel criteria such as design complexity, speed of construction, environment, and aesthetic and construction complexity, Mousavi et al. [15] developed a hybrid FQFD model using fuzzy technique for order performance by similarity to Ideal Solution (TOPSIS) for bridge scheme selecting, which was a complex engineering project.

Lin and Lee [16] presented a model of QFD and FANP to solve NPD problem in TFT-LCD industry. They used fuzzy Delphi method to simplify number of factors in the model and made paired comparisons easier.

Celik et al. [17] proposed an integrated FQFD model for investment decisions of shipping routing in crude oil tanker market. This model used FQFD principles for shipping investment process through substituting HoQ with ship of quality (SoQ). In addition, FAHP and fuzzy axiomatic design (FAD) algorithms were integrated in SoQ in order to reach quantitative results. SoQ framework was tested by a set of periodic data and current trends in tankers market for big companies like Suezmaxes and Aftermaxes.

Khademi-Zare et al. [18] provided two prioritizing models based on FQFD for ranking strategic actions (SAs) of mobile cellular telecommunication in Iran. Considering the gap between current situation and positive ideal situation for customer attribute (CAs), they used TOPSIS for ranking CAs in first model. Using AHP in the second model, more factors have been considered to rank CAs. A fuzzy utility factor, $B_{j}$, was introduced for ranking CAs in both models. Both models were able to consider ambiguity in human judgments and allowed customer-oriented companies like Mobile Communication of Iran (MCI) to use voice of customers for extracting benefits in a more expressive way.

Lin et al. [19] presented a model to analyze environmental requirements of products with linguistic preferences using FQFD and ANP with interdependence relations between environmental production requirements (EPRs) and sustainable product indicators (SPIs). At first, to facilitate main issue of QFD problem, Whats questions of EPRs and Hows questions of SPIs have been made, which were two main components of HoQ. In conjunction with fuzzy set theory and ANP, the systemic analytical approaches were proposed.

Mousavi [15] proposed a systematic decision making process for evaluating conceptual bridge design and selecting the best idea through the new methodology based on integrated optimization. In the first phase, QFD has been employed to translate project requirements to design requirements. Then, the best structure as an alternative was selected by TOPSIS based on weighted criteria achieved from first phase. In this study the rating values regarding each alternative and criteria throughout the phases were described in a fuzzy environment by means of linguistic variables. Finally, a case study was provided to illustrate the implementation process of the integrated methodology for bridge superstructure design.

In his work, Wang [20] utilized FQFD and MCDM methods for optimized modular design. This article integrated FAHP and fuzzy decision making trial and evaluation laboratory (DEMATEL) to achieve weights of DRs and created constructing blocks of optimum modular design. 
Nepal et al. [21] proposed an FAHP framework according to fuzzy set theory, to prioritize customer satisfaction (CS) attributes in target planning for vehicle design. In addition, unlike previous studies, they considered a broad range of technical and strategic factors to evaluate weights. Then, these weights were introduced in target planning by identifying the gap in current CS level. This framework was deployed in Microsoft Excel, so it could be utilized with a limited training in organization. Unlike traditional AHP, FAHP gave QFD team members freedom of estimation, since judgments could vary from very optimistic to very pessimistic.

Zheng et al. [22] presented an evaluation method for integrating fourth-party logistics (4PL) supply chain based on FQFD and AHP. At first, they studied 4PL requirements and introduced them into supply chain design process by QFD. Then, nonvalue processes were eliminated using benchmarking method and supply chain was rebuilt by supply chain fuzzy evaluation theory. Utilizing multiobjective optimizing theory, optimum model of 4PL was achieved by evaluating value. Finally, they used FAHP to present evaluation method of $4 \mathrm{PL}$ integration.

Gungor et al. [23] proposed a fuzzy decision making system (FDMS) based on fuzzy control rules for new product design using FQFD. Customer needs, as inputs of FDMS, were fuzzified and prioritized using membership function concept. DRs were rated by if-then rules. This paper determined fulfillment levels of DRs by FANP and its results were compared with those of proposed FDMS.

Lee and Lin [24] proposed a fuzzy model consisting of FANP and QFD in new product development. Parameters of each phase of QFD were determined through literature review and interviewing with experts and fuzzy Delphi method was utilized for screening important factors. Also for constructing relations within HoQ, fuzzy interpretive structural modeling with FANP was used.

Liu et al. [25] prepared a model for product design and selection using FQFD and MCDM methods. This paper integrated FQFD and product prototype selection and proposed a method for product design selection. $\alpha$-Cuts operation was utilized in QFD for fuzzy set calculations of each component. Competitive analyses as well as relations between TCs were considered too. Considering TCs and product development factors in product prototype selection, an MCDM method was proposed for prototype selection. This method provided product developers with useful information and precise analysis. It is a useful decision aid tool.

Liu and Wang [26] proposed an advanced QFD model with FANP to consider interdependencies within and relations between QFD components. To extend applicability of QFD, authors were seeking to extend QFD from product planning phase for part deploying phase.

Zandi and Tavana [27] proposed a methodology for evaluation and selection of the best e-CRM framework in agile production using FQFD, fuzzy group real option analysis (ROA), and fuzzy TOPSIS method. First, e-CRM frameworks were prioritized according to financially oriented characteristics using an ROA model. Next, the e-CRM frameworks were ranked according to their customer-oriented characteristics using a hybrid fuzzy group permutation and a four-phase fuzzy quality function deployment (QFD) model with respect to three main perspectives of agile manufacturing (i.e., strategic, operational, and functional agilities). Finally, the best agile e-CRM framework was selected using a TOPSIS model.

Zarei et al. [28] proposed a hybrid methodology of AHPQFD to increase leanness of food supply chain. Linking lean attributes (LAs) and lean enablers (LEs), this study used quality function deployment (QFD) to identify viable LEs to be practically implemented in order to increase the leanness of the food chain. Furthermore, triangular fuzzy numbers were used to deal with linguistic judgments expressing relationships and correlations required in QFD. FAHP was employed to prioritize LAs.

Yousefie et al. [29] proposed an original approach for the management tools selection based on the quality function deployment (QFD) approach. Specifically, the research addressed the issue of how to deploy the house of quality (HOQ) to effectively and efficiently improve management tools selection processes and thus company satisfaction about its excellence achievement. Entropy method was used to perform competitive analysis and calculation weights of competitive priorities. Then, FAHP was employed to prioritize management tools. Presented hybrid models and methodologies by Karsak and Özogul [30], Huang and Li [31], Wang and Chin [32], Tolga and Alptekin [33], Karsak et al. [34], and Ozdemir and Ayag [35] were discussed in Section 2.8 .

2.3. Fuzzy Group Decision Making Models. Zhang and Chu [36] introduced a model for selection of multiple design schemes of complex products based on QFD and fuzzy group decision making. They divided the scheme to parts and evaluated weights of each part using group decision making in QFD and rank the designs. In addition to selection of optimized design, QFD was employed to integrate customer requirements into design. This paper also used group decision making for determining relations between characteristics.

Büyüközkana et al. [37] proposed a new fuzzy group decision making method for product design by QFD. In their model, inputs of QFD process were both quantitative and qualitative. Quantitative data was translated to qualitative one; then fuzzified and finally weights of TCs were computed.

Liu [38] used a fuzzy group decision making with risk-taking attribute to deploy QFD, because they thought decision makers' opinions about risk taking were different (optimistic, normal, and conservative). Finally, TCs were prioritized and HoQ was completed.

Zhang and Chu [36] proposed a fuzzy group decision making to aggregate multiformat and multigranularity judgments of decision makers based on two optimizing models (logarithmic least square and weighted least square) for constructing HoQ. Logarithmic least square model and two normalized formulae were utilized to solve fuzzy paired comparisons matrices and normalizing evaluations in linguistics format. Then, weighted least square model was used to aggregate ultimate normalized multigranularity evaluations. Sanayei et al. [39] utilized MCDM model of Vlse Kriterijumska Optimizacija I Kompromisno Resenje (VIKOR), 
which means multicriteria optimization and compromise solution, in association with fuzzy group decision making for supplier selection. VIKOR method is a multicriteria decision making method for solving problems which have inconsistent criteria. It selects an alternative which has the least distance from ideal solution.

Lin et al. [40] employed QFD and fuzzy group decision making for service innovation. This study developed a scientific framework for tourism service management from epistemology perspective. This article used FQFD and fuzzy group decision making to analyze various service evaluation criteria. In particular, the methodology allowed the identification of service attributes perceived to affect service design performances from the tourist's point of view, enabling the assessment of possible gaps between tourists' and hotel's perception of service delivery. To assess viable strategic designs, in the proposed approach they introduced a utility factor, considering the costs of implementation for each "How." Wanga and Xionga [41] provided an integrated approach of group decision making based on linguistic variables for QFD applications. Proposed methodology does its computations with words-without converting to fuzzy numbers-so information loss risk is low. Hybrid model of Liu et al. [26] is discussed in Section 2.8.

2.4. Metaheuristic Methods. According to meta-heuristic algorithms' ability to solve complex problems, they can be used in different stages of QFD process. Discussed articles often use meta-heuristic methods to identify relations between CNs and TCs.

Hsiao and Liu [42] proposed a neurofuzzy evolutionary approach for product design. Their model was based on artificial intelligence including fuzzy theory, backpropagation neural network (BPN), and genetic algorithm (GA), along with morphological analysis to synthesize, evaluate, and optimizate of product design. Fuzzy logic was utilized for modeling imprecise market information, BPN for determining relations between CNs and design parameters, morphological analysis for constructing design alternatives, and finally GA was used to select optimum design.

Lin et al. [40] prepared an intelligence model to estimate product design time (PDT) using intelligence method. Due to lack of information in early stage of product development, this model utilized fuzzy logic to complete HoQ. This model employed QFD to extract DRs from CNs. Then a fuzzy neural network was built to combine data and estimated PDT, which made use of fuzzy comprehensive evaluation to simplify structure. In a word, the whole estimation method consisted of four steps: time factors identification, product characteristics extraction by QFD and function mapping pattern, FNN learning, and PDT estimation. Finally, to illustrate the procedure of the estimation method, the case of injection mold design was studied. This model had some limitations. It was inapplicable for developing brand new products, because the influencing weights of linguistic variables obtained by experience or experiment were important for the parsimonious FNN model.

As the functional relationships between customer requirements and engineering characteristics in QFD are uncertain, unclear, and fuzzy, Huang and Li [31] proposed radial basis function (RBF) to determine the functional relationships for QFD and QFD functional relationships model based on RBF. According to RBF neural network, nonlinear mapping space from the input space to the output can be realized, and optimal relationships pattern of the input and output would be obtained. The customer requirements and engineering characteristics in QFD constituted the input and output of the RBF.

The optimal relationships were constructed through the neural network training. Wanga and Xionga [41] analyzed the limitations of traditional methods by using the product planning HoQ; the available linguistic terms based on experts' knowledge, and with the artificial neural network, were introduced to realize neural network-based fuzzy reasoning. The final importance of the technical requirements was evaluated reasonably and effectively. This model considered market competitiveness and technical competitiveness. The importance of technical requirement was determined through four steps: (1) acquisition of customer requirements and ranking of their importance measures, (2) establishment of technical requirements and their relations with customer requirements, (3) establishment of market competitiveness and technical competitiveness, and (4) evaluation of technical requirement importance with competitiveness.

Lee and Lin [24] proposed an ANN-based dynamic FQFD method in order to solve the dynamic and fuzzy nature of QFD; they solved the problem of the dynamic nature by using neural network method, while trapezoidal fuzzy number for its ambiguity was introduced. Firstly, a combined method with neural networks and FQFD was established; after learning and training, the method could quickly and effectively deliver customer requirements to the products designers. This model could solve a non-linear problem and met the non-linear changes in customer needs. Hybrid model of Liu [25] and Karsak and Özogul [30] paper were described in Section 2.8.

2.5. Fuzzy Regression Models (Linear and Nonlinear). These models were used to complete HoQ and their main focus was on finding relations between parameters of HoQ. Chen and Chen [13] utilized a fuzzy nonlinear possibilistic regression approach to model product planning (first phase of QFD). The model was able to incorporate both qualitative and quantitative data in determining relations between CRs and DRs as well as within DRs. Using linear regression, some coefficients became crisp because of linear programming nature. Therefore, they used nonlinear regression in their model. TFNs were used in this model. Sener and Karsak [8] and Karsak et al. [34] studies were discussed in Section 2.8.

2.6. Models Proposed to Prioritize CRs. Identifying CNs and their importance weight is first step of QFD process. Due to its importance, some papers have been focused on determining CNs and their importance weight. Lai et al. [43] proposed a new methodology in their articles which considered competitors information. This paper considered competitive environment and product's current performance. 
The proposed algorithm was complicated, but the authors claimed that its solutions were more accurate than similar models. Mehdizadeh [44] used fuzzy centroid-based method and considered competitive environment to rank CRs. He employed both normal and nonnormal numbers. All of previous studies employed normal fuzzy numbers which resulted in misleading solutions in case of non-normal fuzzy numbers. Using fuzzy centroid-based method, this paper solved the problem.

2.7. Hybrid Models. Some of discussed models encompass more than one model of above ones, so we discussed them under subgroup of hybrid models. Using fuzzy set theory and Euclidean distance, Guo et al. [45] put forward a methodology called Euclidean space distances weighting ranking method. They applied this method in fuzzy AHP. This method satisfied additive consistent fuzzy matrix. In addition to designing an algorithm for calculating weights, they developed a module to design new product based on customer needs weight calculation model. Sener and Karsak [8] used an optimization model and fuzzy regression on the basis of non-linear programming to determine target values of TR. Using linear models, regression coefficients approached to zero and, due to this, they used nonlinear models to determine functional relationships between CRs and TRs and within them. Finally, using a fuzzy mathematical programming model, target levels of TRs have been achieved. This fuzzy mathematical programming model incorporated both center values and spread values of parametric estimations of functional relationships in optimization process and, thus, avoided loss of information in design phase.

Liu [25] used a fuzzy group decision making model in association with genetic algorithm in QFD process to complete HoQ and calculation of weights of TRs. The ranking was done in two phases according to budget and time constraints.

Huang and Li [31] employed BP neural network and AHP in QFD fuzzy to determine key technology of product planning and designing. First, they used AHP to determine weights of CRs and then, as the relationships between TRs and CRs, TRs and part characteristics in QFD were uncertain, nonlinear and fuzzy BP neural network was presented to determine these relationships. After determining weights, part characteristics were identified using QFD and key technology of production was selected.

Karsak and Özogul [30], in a paper titled an integrated decision making approach for ERP system selection, they presented a new decision framework for selecting ERP system based on QFD, fuzzy linear regression, and zero-one goal programming (ZOGP). Proposed framework considered both company requirements and features of ERP system and provided a tool not only to link company requirements and features of ERP system but also to interact between them through applying QFD principles. Using fuzzy linear regression, target level of ERP characteristics and reachable maximum values of CNs were achieved. Finally, ZOGP was employed to select ERP system which minimized weights aggregate of deviations from reachable maximum values of organizational needs.
Wang and Chin [32], used fuzzy AHP to prioritize characteristics in QFD. This model utilized linear goal programming (LGP) to calculate normalized fuzzy weights and pairwise comparisons matrices of AHP. Proposed LGP method was tested by three numerical examples including new product development (NPD). The results showed that LGP method can derive precise fuzzy weights for perfectly consistent fuzzy comparison matrices and normalized optimal fuzzy weights for inconsistent fuzzy comparison matrices on the basis of minimum deviation. It was also shown that fuzzy AHP can be used as a very useful decision support tool for NPD project screening.

Mu et al. [46] presented an integrated model of fuzzy multiobjective model and Kano's model to determine nonlinear relationships in HoQ matrix. They considered firm's budget as a constraint for the model and utilized fuzzy multiobjective model to achieve maximum customer satisfaction considering the constraint.

Karsak et al. [34] utilized ANP and GP in QFD to select TRs, emphasizing design process according to given targets. This algorithm included two phases. At the first phase, HoQ was constructed using ANP, and at the second phase, TRs that should be focused were determined using ZOGP.

Tolga and Alptekin [33] integrated QFD with fuzzy compromise-based goal programming to identify how much product features should be improved. ANP is utilized to evaluate inner dependencies within customer needs, product attributes, and also the relationships between them. The constraints of compromise-based goal programming included manufacturer budget and product competitive performance in market.

Ozdemir and Ayag [35] proposed a model for NPD multiobjective problem and its solution with intelligent approach. They combined multiattribute method of TOPSIS and multiobjective method of goal programming (GP) as well as economic analysis. Economic analysis was used for demand changes during product life cycle. Fuzzy equivalent worth of each new product alternative was determined using fuzzy life cycle monetary input, and results were input to the multicriteria analysis. The selected multicriteria analysis tool was TOPSIS in the paper and some additional judgmental criteria were also considered to rank new product alternatives. The preference weights used to rank alternatives were fed to a goal programming model which made an ultimate selection of new product(s) to be produced in the manufacturing system under capacity, sales potential, and workforce balance constraints. The goal programming model had an objective of minimizing the weighted sum of positive deviation from target of total cost and negative deviation of target total preference weights. The proposed approach was implemented using real data of a continuous production system for the need of introducing new products into market.

Wang [20] integrated QFD with multiattribute decision making (MCDM) models for optimal modular design. This paper combined fuzzy AHP and fuzzy DEMATEL to develop marketing-driven product. Fuzzy AHP was used to determine important weight of CNs; then fuzzy DEMATEL was applied to achieve design requirements and to construct 
common/specific building blocks for achieving an optimal modular design.

Gungor et al. [23] developed a fuzzy decision making system (FDMS) based on fuzzy control rules to design new product using QFD which considered CNs as factors. Customer needs were determined as input variables and fuzzified using membership function concept. Weights of these factors were fuzzified to ensure the consistency of the decision maker while assigning the importance of each factor over another. By applying IF-THEN decision rules, DRs of the firm were scored. This paper also used fuzzy analytic-network process (FANP) to determine the fulfillment levels of DRs of the firm and its results were compared with FDMS's ones.

Sanayei et al. [39] used MCDM model of VIKOR (Vlse Kriterijumska Optimizacija I Kompromisno Resenje means multicriteria optimization and compromise solution) along with group decision making methods for selecting supplier. VIKOR was an MCDM method for solving problems with conflicting and noncommensurable (different units) criteria and choosing the alternative that was closest to ideal solution.

2.8. Other Methods. Kahraman et al. [5] used fuzzy ranking methods for evaluating DRs. Fuzzy ranking methods were rarely used in previous studies. This paper used three fuzzy ranking methods in PVC windows industry and finally compared them using sensitivity analysis.

\section{Applications of FQFD}

Some of papers discussed FQFD applications. Although QFD had numerous applications and traditional QFD has been deployed in lots of firms, here we discussed most important applications of FQFD. The most important application of QFD was supply chain management (SCM). Moreover, there were some papers in product design and other applications.

3.1. Supply Chain Management (SCM). In a paper about selecting supplier, Bevilacqua et al. [47] proposed a new method which translated $\mathrm{HoQ}$ as problem of a huge company of clutch coupling production.

Zhang and Chu [48] put forward a new method for contingency management of 3rd party logistics (3PL). They suggested a multiobject framework using FQFD and group decision making. In addition to contingency management, risk management was also considered.

Wang et al. [49] proposed a practicable method for determining customization place of service products logistics to improve capability of 3PL customized servicing. First, they used FQFD to import CNs in locating process. Then, a multiobject integer programming model was developed to determine optimum locating program under constraints of 3PL interior sources and payment values of buyer firm for outsourcing.

Rau and Fang [50] proposed a combined model of FQFD and TRIZ to solve conflicts within design characteristics for packaging design in notebooks logistic. In this model, first, design requirements and design characteristics were specified. Then their relationships were identified based on language variables using experts' opinions using HoQ. Weight of design characteristics was calculated using fuzzy integral method. Finally, modifications and innovation principles are determined for solving conflicts of product pack design problem corresponding to priority of design characteristics.

Bottani and Rizzi [51] suggested a method for customer service management in supply chain using FQFD. The main intention was using HoQ to improve logistics processes effectively and efficiently. They estimated distance between firm's performance in logistic services and customer needs. According to customer importance, CNs were weighted to identify key factors for services improvement. The study began with identifying characteristics which purchased product for satisfying customers (what variables). Then it created criteria for supplier evaluation using a final ranking based on fuzzy proportion index for conclusion. All of process was deployed using fuzzy numbers. Using a fuzzy algorithm allowed company to define importance weights of What, relationship rates between Whats and Hows, and effect of each potential supplier by language variables. This paper attended specifically to different personal evaluations in HoQ accomplishment process and fuzzy triangular numbers were suggested to consider ambiguity in language evaluations.

Amin and Razmi [52] suggested a fuzzy integrated model based on firm's strategy for managing, evaluation, and supplier development. In the first phase, QFD was used to rank the best ISPs based on qualitative criteria. In the first phase, QFD was employed for ranking best ISPs based on qualitative criteria. Then, a quantitative model was used to consider quantitative criteria. Finally, two models were developed and the best ISP was selected. In the next phase, a new algorithm was developed to evaluate selected ISPs in three features: customer, performance, and competition. Fuzzy logic and triangular fuzzy numbers were used for dealing with ambiguity in human thinking. A case study brought forward to show evaluation and selection phases of ISPs.

Sohn and Choi [53] used QFD for SCM considering reliability. They developed an FQFD model to determine relationships between customer needs and design characteristics according to reliability test. They employ QFD to determine relationships between CNs and design characteristics in each supply chain. Then, they assumed these relationships were reversible and considered end user needs as a function of reliability test performance variables in the last chain of product design process. Finally, fuzzy MCDM was utilized to find an optimum solution set regarding demanded reliability performance. Other works including Gunasekaran et al. [14], Lin et al. [40], Zheng et al. [22], and Zarei et al. [28] were discussed in Section 2.

3.2. Product Design. Due to law restrictions and public pressures, many companies were making products consistent with environmental concerns. Many of these products were produced and sent to market so far, but most of them were rejected by customers and couldn't gain a market share. It seemed that they faced this problem because they just considered environmental conditions and neglected customer 
needs [54]. Recently, some studies have been focused on this problem to solve it by considering both environmental and customer requirements simultaneously using FQFD.

In a paper titled as "Integration of environmental considerations in quality function deployment by using fuzzy logic," Kuo et al. [54] proposed a developed Eco-QFD model to form a design team considering both environmental concerns and customer satisfaction by using QFD. A fuzzy group method was applied to Eco-QFD for product development planning to reduce the vagueness and uncertainty in a group decision making process. This fuzzy multiobjective model not only considered the overall customer satisfaction but also encouraged enterprises to produce an environmentally friendly product. With an interactive approach, the optimal balance between environmental acceptability and overall customer satisfaction could be obtained. Finally, a case study illustrating the application of the proposed model was also provided. Kuo and Hung [55] proposed a fuzzy EcoQFD model to design products based on environmental considerations. They used a fuzzy multiobjective model to aid the design team in choosing target levels for engineering characteristics. Paper of Lin et al. [40] about environmental production was discussed in Section 2.2.

Lin et al. [40] employed FQFD to analyze Island hotels management by using lingual preferences. They proposed an approach for managing internal and external services as well as service innovations based on an FQFD framework. That was a methodology adapted to service development properly. The paper addressed how to apply HoQ to improve hotel services innovation process and tourists satisfaction efficiently and effectively. Fuzzy logic provided a methodology to deal with lingual judgments nature in $\mathrm{HoQ}$. At the end a case study was discussed to examine model accuracy. Work of Lin et al. [40] on service innovation was discussed in Section 2.3.

3.3. Other Applications. Jia and Bai [56] suggested a method to develop manufacturing strategy using QFD. This method consisted of 11 steps and used QFD as a transferring tool to relate competitive factors with manufacturing decision groups (such as structural and infrastructural decision groups) and a main tool in different stages of developing manufacturing strategy. This paper also integrated fuzzy set theory with $\mathrm{HoQ}$ to deal with vagueness of decision process inputs.

Şen and Baraçlı [57] presented a methodology to find software selection requirements for organizations based on FQFD. They proposed a QFD approach to determine which nonfunctional requirements reported by recent studies were important in software selection decision making and combined it with functional requirements. The proposed solution not only helped decision makers to determine software selection's characteristics and criteria, but also provided their importance weights.

Zhang and Chu [48], using rough set theory, proposed a new methodology for FQFD to facilitate decision making in early stages of product development. At the end, they compared their proposed method with traditional FQFD and found result of proposed method more accurate.
TABLE 1: The frequency of proposed methodologies for FQFD.

\begin{tabular}{llc}
\hline ID & Method & $\begin{array}{c}\text { Number of } \\
\text { research }\end{array}$ \\
\hline 1 & $\begin{array}{l}\text { Fuzzy linear and nonlinear programming } \\
\text { models }\end{array}$ & 53 \\
2 & $\begin{array}{l}\text { Fuzzy regression models (linear and } \\
\text { nonlinear) }\end{array}$ & 3 \\
3 & Metaheuristic methods & 6 \\
4 & Hybrid models & 13 \\
5 & Fuzzy group decision making models & 8 \\
6 & $\begin{array}{l}\text { Multicriteria decision making (MCDM) } \\
7\end{array}$ & Models \\
8 & Other methods & 29 \\
\hline
\end{tabular}

Yan et al. [58] employed FQFD to design decision support system for hazardous material road transportation accidents. First, they identified problem of decision support system plan selection including requirements of governmental organization and transportation companies. Then, they used QFD to translate these requirements to technical characteristics of decision support system.

\section{Conclusion}

As mentioned, nowadays FQFD is used as a powerful tool in designing and developing products and decision making from supplier selection to Eco-design product development. In comparison with traditional QFD, using fuzzy logic is unavoidable. Actually, regarding application of lingual variables in paired comparisons, ratings, and weightings, using crisp numbers leads to lose information. Combining fuzzy logic and QFD has made a new methodology named fuzzy QFD. Using many case studies showed that this methodology is effective and reliable. In this review, after analyzing papers published between 2000 and 2011, we categorized papers in two major groups of (i) proposed models of FQFD and (ii) QFD employed applications. The first consisted of 8 subgroups and the second topic included 3 subgroups. Literature review showed that FQFD has been used mostly in supply chain management. After discussing and analyzing papers, we identified models' weakness, strength points, and literature vacancies and proposed some directions for future research. The frequency of proposed methodologies for FQFD (Table 1) showed that fuzzy linear and nonlinear programming models have been used 53 times with the first rank. Therefore it seems that since linear and nonlinear programming models can find the optimum solution, mostly researches tend to use this methodology.

\section{Future Research}

Most of discussed papers only studied first phase of QFD (i.e., quality matrix) and just completed HoQ. This was maybe due to importance of this stage, but to deliver a product according 
to customer requirements in target market, we should complete all phases of QFD. Results of first phase were weighted (or prioritized) TCs which should be translated to part characteristics and process requirements, respectively, so we could produce a product appropriate for target market. Hence it seems essential to extend proposed models for all phases of QFD. Regarding HoQ, other problem is its big size and complexity in many NPD problems. This issue, especially in fuzzy environment, caused greater complexity. Metaheuristic algorithms such as artificial neural networks (ANN), which were used to determine complex and non-liner relations, were one of feasible solutions. For this problem, most of researchers assumed that relations between TCs and CNs as well as relations within TCs were linear in HoQ. On the other hand, model's applicability and being user-friendly were more important than model. Introducing fuzzy logic with its comprehensive, long, and time-consuming calculation of the models has stopped many models in the theory phase and does not allow these models to become practicable. A good solution to this problem is to design some modules and software which make calculations easier and allow users to get their outputs by a little change in inputs. Another way to increase users' interest in proposed models is using expert and decision support systems which decrease calculations. It's noteworthy that designing databases is an effective way for gathering, maintenance, and easier access to CNs for next developments of products design and process risk analysis is another concept which is less studied in papers. Even the most optimistic people accept a percentage of risk for process. We should consider process risk in addition to QFD process and method execution because running the project in organization needs capital. This area needs many studies to be carried out, too. Other issue, which is less considered in papers, is use of appropriate fuzzy number. We should investigate and find suitable kind of fuzzy numbers for each especial application. Most of researches have used triangular fuzzy number (TFN) because their calculations were easier than other fuzzy numbers. Nevertheless, using TFNs might cause losing information in some cases. Also most of studies use normal fuzzy numbers. In this case, appropriate fuzzy number-normal or abnormal-should be determined. In some cases, algebraic operations are used for working with fuzzy sets which can lead to wrong results.we should use fuzzy operation such as $\mathrm{x}$-cuts in these cases. Also, defuzzifying of fuzzy numbers many lead to lose information, so we should try not to defuzzify in early stages of calculations and use fuzzy operations as far as we can. Other proposed method to deal with this issue is using lingual variables and avoiding translating them into fuzzy numbers [59].

Although QFD has been invented to design product according to customer needs, we cannot just consider CNs and forget about market competiveness. It is possible to increase your market share even with a product lower than customer expectation because of market low competitiveness and vice versa. Hence, in addition to attention to customer needs, one should use competition analysis to determine strengths, weaknesses, target market situation, and sale points. It should be noticed that customer preferences may change after introducing product to market due to different factors [8]. So, models should be developed in a way that can anticipate changes in customer needs and put this anticipating in product design after initial introducing of product. Although fuzzy linear and nonlinear programming models have been used frequently in FQFD process, most of their application is in determining of satisfaction level of process characteristics according to existing constraints. Most of papers used linear methods and there are a few papers used nonlinear models. In case of multiattribute models, one must notice differences between AHP and ANP methods. Although fuzzy AHP is easier and less time consuming than fuzzy ANP, but when there are interdependencies between parameters, one must use fuzzy ANP. Increasing application of FAHP in papers, in spite of interdependencies between TCs and CNs, is concerning and should be reviewed. Goal programming is one of the MCDM methods and used widely in FQFD process. Goal programming includes several methods such as zero-one goal programming and weighting goal programming. Most of studies use zero-one goal programming; it should be investigated when we can choose one of GP methods. Using GP in combination with other methods is another important point. We cannot fulfill all needs of design team with just these methods. Also, number of employed constraints in this decision making methods should be selected according to company situation, kind of problem and its complexity, and market competitiveness situation, so its results could be applied in real world. While many GP models consider coefficients as crisp numbers, they should be considered as fuzzy numbers, according to fuzzy environment and operations. It decreases risk of information lost.

Many of discussed papers used hybrid models. In spite of big size of calculations, it seems that combination of different methods is a promising trend in FQFD. They can be combined to cover weaknesses of each other and use their strengths. It's better to compare results of all used methods to reach the best method. Using fuzzy group decision making models is another promising trend which seems necessary because of several decision makers (QFD team) who were involved in QFD process.

Metaheuristic algorithms are another new method employed in FQFD. The most frequent meta-heuristic algorithms used in FQFD are genetic algorithm (GA) and artificial neural networks (ANN). According to increasing trend of using these algorithms, it is expected that other meta-heuristic algorithms will be used in QFD, too. These methods were mostly used to determine relations between characteristics especially in quality matrix (or HoQ). They can be used to calculate target values of TCs and determine fulfillment level of these characteristics.

In the case of QFD applications, QFD can be used in all industries (both manufacturing and service), but, among papers published in different databases and discussed here in this review, QFD was used SCM and logistics more than other discussed applications. Using QFD to develop products according to environmental considerations is a new, promising trend. QFD applications in designing expert systems and decision support systems have a long way to go. In these two last cases, there is a mutual relation between QFD 
and them. We can use QFD to select and develop DSS and expert systems; on the other side, these systems can be used to deploy QFD's proposed models easier to make them userfriendly by decreasing calculations size.

\section{References}

[1] L. H. Chen and W. C. Ko, "Fuzzy approaches to quality function deployment for new product design," Fuzzy Sets and Systems, vol. 160, no. 18, pp. 2620-2639, 2009.

[2] L. K. Chan and M. L. Wu, "A systematic approach to quality function deployment with a full illustrative example," Omega, vol. 33, no. 2, pp. 119-139, 2005.

[3] L. H. Chen and W. C. Ko, "Fuzzy linear programming models for NPD using a four-phase QFD activity process based on the means-end chain concept," European Journal of Operational Research, vol. 201, no. 2, pp. 619-632, 2010.

[4] X. F. Liu and J. Yen, "Analytic framework for specifying and analyzing imprecise requirements," in Proceedings of the 18th International Conference on Software Engineering, pp. 60-69, IEEE Computer Society Press, Los Alamitos, Calif, USA, March 1996.

[5] C. Kahraman, T. Ertay, and G. Büyüközkan, "A fuzzy optimization model for QFD planning process using analytic network approach," European Journal of Operational Research, vol. 171, no. 2, pp. 390-411, 2006.

[6] L. H. Chen and W. C. Ko, "A fuzzy nonlinear model for quality function deployment considering Kano's concept," Mathematical and Computer Modelling, vol. 48, no. 3-4, pp. 581-593, 2008.

[7] X. G. Luo, J. F. Tang, and D. W. Wang, "An optimization method for components selection using quality function deployment," International Journal of Advanced Manufacturing Technology, vol. 39, no. 1-2, pp. 158-167, 2008.

[8] Z. Sener and E. E. Karsak, "A decision model for setting target levels in quality function deployment using nonlinear programming-based fuzzy regression and optimization," International Journal of Advanced Manufacturing Technology, vol. 48, no. 9-12, pp. 1173-1184, 2010.

[9] K. J. Kim, H. Moskowitz, A. Dhingra, and G. Evans, "Fuzzy multicriteria models for quality function deployment," European Journal of Operational Research, vol. 121, no. 3, pp. 504-518, 2000.

[10] C. K. Kwong and H. Bai, "A fuzzy AHP approach to the determination of importance weights of customer requirements in quality function deployment," Journal of Intelligent Manufacturing, vol. 13, no. 5, pp. 367-377, 2002.

[11] I. Erol and W. G. Ferrell, "A methodology for selection problems with multiple, conflicting objectives and both qualitative and quantitative criteria," International Journal of Production Economics, vol. 86, no. 3, pp. 187-199, 2003.

[12] G. Büyüközkan, T. Ertay, C. Kahraman, and D. Ruan, "Determining the importance weights for the design requirements in the house of quality using the fuzzy analytic network approach," International Journal of Intelligent Systems, vol. 19, no. 5, pp. 443-461, 2004.

[13] L. H. Chen and M. C. Weng, "An evaluation approach to engineering design in QFD processes using fuzzy goal programming models," European Journal of Operational Research, vol. 172, no. 1, pp. 230-248, 2006.

[14] N. Gunasekaran, S. Rathesh, S. Arunachalam, and S. C. L. Koh, "Optimizing supply chain management using fuzzy approach,"
Journal of Manufacturing Technology Management, vol. 17, no. 6, pp. 737-749, 2006.

[15] S. M. Mousavi, H. Malekly, H. Hashemi, and S. M. H. Mojtahedi, "A two-phase fuzzy decision making methodology for Bridge Scheme Selection," in Proceedings of theIEEE International Conference on Industrial Engineering and Engineering Management (IEEM '08), pp. 415-419, December 2008.

[16] C. Y. Lin and A. H. I. Lee, "Preliminary study of a fuzzy integrated model for new product development of TFT-LCD," in Proceedings of the IEEE International Conference on Service Operations and Logistics, and Informatics (IEEE/SOLI '08), pp. 2689-2695, October 2008.

[17] M. Celik, S. Cebi, C. Kahraman, and I. D. Er, "An integrated fuzzy QFD model proposal on routing of shipping investment decisions in crude oil tanker market," Expert Systems with Applications, vol. 36, no. 3, pp. 6227-6235, 2009.

[18] H. Khademi-Zare, M. Zarei, A. Sadeghieh, and M. Saleh Owlia, "Ranking the strategic actions of Iran mobile cellular telecommunication using two models of fuzzy QFD," Telecommunications Policy, vol. 34, no. 11, pp. 747-759, 2010.

[19] L. Z. Lin, W. C. Chen, and T. J. Chang, "Using FQFD to analyze island accommodation management in fuzzy linguistic preferences," Expert Systems with Applications, vol. 38, no. 6, pp. 7738-7745, 2011.

[20] C. H. Wang, "An integrated fuzzy multi-criteria decision making approach for realizing the practice of quality function deployment," in Proceedings of the IEEE International Conference on Industrial Engineering and Engineering Management (IEEM '10), pp. 13-17, December 2010.

[21] B. Nepal, O. Yadav, and A. Murat, "A fuzzy-AHP approach to prioritization of CS attributes in target planning for automotive product development," Expert Systems with Applications, vol. 37, pp. 6775-6786, 2010.

[22] L. Zheng, T. Pan, and G. Yan, “The process integration evaluation method of the fourth party logistics using fuzzy theory," in Proceedings of the 4th International Conference on Management of e-Commerce and e-Government (ICMeCG '10), pp. 313-316, October 2010.

[23] Z. Gungor, E. K. Delice, and S. E. Kesen, "New product design using FDMS and FANP under fuzzy environment," Applied Soft Computing, vol. 11, no. 4, pp. 3347-3356, 2011.

[24] A. H. I. Lee and C. Y. Lin, "An integrated fuzzy QFD framework for new product development," Flexible Services and Manufacturing Journal, vol. 23, no. 1, pp. 26-47, 2011.

[25] H. T. Liu, "Product design and selection using fuzzy QFD and fuzzy MCDM approaches," Applied Mathematical Modelling, vol. 35, no. 1, pp. 482-496, 2010.

[26] H. T. Liu and C. H. Wang, "An advanced quality function deployment model using fuzzy analytic network process," Applied Mathematical Modelling, vol. 34, no. 11, pp. 3333-3351, 2010.

[27] F. Zandi and M. Tavana, "A fuzzy group quality function deployment model for e-CRM framework assessment in agile manufacturing," Computers and Industrial Engineering, vol. 61, no. 1, pp. 1-19, 2011.

[28] M.Zarei, M. B. Fakhrzad, and M. Jamali Paghaleh, "Food supply chain leanness using a developed QFD model," Journal of Food Engineering, vol. 102, no. 1, pp. 25-33, 2011.

[29] S. Yousefie, M. Mohammadi, and J. H. Monfared, "Selection effective management tools on setting European Foundation for Quality Management (EFQM) model by a quality function 
deployment (QFD) approach," Expert Systems with Applications, vol. 38, no. 8, pp. 9633-9647, 2011.

[30] E. E. Karsak and C. O. Özogul, "An integrated decision making approach for ERP system selection," Expert Systems with Applications, vol. 36, no. 1, pp. 660-667, 2009.

[31] L. Huang and X. Li, "Research on determining the key technology of new product plan and design," in Proceedings of the IEEE International Conference on Robotics and Biomimetics (ROBIO '08), pp. 1532-1537, Bangkok, Thailand, February 2009.

[32] Y. M. Wang and K. S. Chin, "A linear goal programming priority method for fuzzy analytic hierarchy process and its applications in new product screening," International Journal of Approximate Reasoning, vol. 49, no. 2, pp. 451-465, 2008.

[33] E. Tolga and S. E. Alptekin, "Product evaluation and development process using a fuzzy compromise-based goal programming approach," Journal of Intelligent and Fuzzy Systems, vol. 19, no. 4-5, pp. 285-301, 2008.

[34] E. E. Karsak, S. Sozer, and S. E. Alptekin, "Product planning in quality function deployment using a combined analytic network process and goal programming approach," Computers and Industrial Engineering, vol. 44, no. 1, pp. 171-190, 2003.

[35] R. G. Ozdemir and Z. Ayag, "Fuzzy ANP-based modified TOPSIS for machine tool selection problem," in Proceedings of the 16th International Working Seminar on Production Economics (IWSPE '10), Innsbruck, Austria, March 2010.

[36] Z. Zhang and X. Chu, "Fuzzy group decision-making for multiformat and multi-granularity linguistic judgments in quality function deployment," Expert Systems with Applications, vol. 36, no. 5, pp. 9150-9158, 2009.

[37] G. Büyüközkana, O. Feyzioğlu, and D. Ruanb, "Fuzzy group decision-making to multiple preference formats in quality function deployment," Computers in Industry, vol. 58, no. 5, pp. 392-402, 2007.

[38] H. T. Liu, "The extension of fuzzy QFD: from product planning to part deployment," Expert Systems with Applications, vol. 36, no. 8, pp. 11131-11144, 2009.

[39] A. Sanayei, S. Farid Mousavi, and A. Yazdankhah, "Group decision making process for supplier selection with VIKOR under fuzzy environment," Expert Systems with Applications, vol. 37, no. 1, pp. 24-30, 2010.

[40] L. Z. Lin, L. C. Huang, and H. R. Yeh, "Fuzzy group decisionmaking for service innovations in quality function deployment," Group Decision and Negotiation, vol. 21, no. 4, pp. 495-517, 2011.

[41] X.-T. Wanga and W. Xionga, "An integrated linguistic-based group decision-making approach for quality function deployment," Expert Systems with Applications, vol. 38, no. 12, pp. 14428-14438, 2011.

[42] S. W. Hsiao and E. Liu, "A neurofuzzy-evolutionary approach for product design," Integrated Computer-Aided Engineering, vol. 11, no. 4, pp. 323-338, 2004.

[43] F. Lai, D. Li, Q. Wang, and X. Zhao, "The information technology capability of third-party logistics providers: a resourcebased view and empirical evidence from China," Journal of Supply Chain Management, vol. 44, no. 3, pp. 22-38, 2008.

[44] E. Mehdizadeh, "Ranking of customer requirements using the fuzzy centroid-based method," International Journal of Quality and Reliability Management, vol. 27, no. 2, pp. 201-216, 2010.

[45] M. Guo, J. B. Yang, K. S. Chin, H. W. Wang, and X. B. Liu, "Evidential reasoning approach for multiattribute decision analysis under both fuzzy and Interval uncertainty," IEEE Transactions on Fuzzy Systems, vol. 17, no. 3, pp. 683-697, 2009.
[46] T. Mu, A. K. Nandi, and R. M. Rangayyan, "Classification of breast masses via nonlinear transformation of features based on a kernel matrix," Medical and Biological Engineering and Computing, vol. 45, no. 8, pp. 769-780, 2007.

[47] M. Bevilacqua, F. E. Ciarapica, and G. Giacchetta, "A fuzzyQFD approach to supplier selection," Journal of Purchasing and Supply Management, vol. 12, no. 1, pp. 14-27, 2006.

[48] Z. Zhang and X. Chu, "A selection model for multiple design schemes of complex product," in Proceedings of the 4th International Conference on Fuzzy Systems and Knowledge Discovery (FSKD '07), pp. 483-487, August 2007.

[49] F. Wang, X. H. Li, W. N. Rui, and Y. Zhang, "A fuzzy QFD-based method for customizing positioning of logistics Service products of 3PLS," in Proceedings of the International Conference on Wireless Communications, Networking and Mobile Computing (WiCOM '07), pp. 3331-3334, September 2007.

[50] H. Rau and Y. T. Fang, "Conflict resolution of product package design for logistics using the triz method," in Proceedings of the International Conference on Machine Learning and Cybernetics, pp. 2891-2896, July 2009.

[51] E. Bottani and A. Rizzi, "Strategic management of logistics service: a fuzzy QFD approach," International Journal of Production Economics, vol. 103, no. 2, pp. 585-599, 2006.

[52] S. H. Amin and J. Razmi, "An integrated fuzzy model for supplier management: a case study of ISP selection and evaluation," Expert Systems with Applications, vol. 36, no. 4, pp. 8639-8648, 2009.

[53] S. Y. Sohn and I. S. Choi, "Fuzzy QFD for supply chain management with reliability consideration," Reliability Engineering and System Safety, vol. 72, no. 3, pp. 327-334, 2001.

[54] I. H. Kuo, S. J. Horng, T. W. Kao, T. L. Lin, C. L. Lee, and Y. Pan, "An improved method for forecasting enrollments based on fuzzy time series and particle swarm optimization," Expert Systems with Applications, vol. 36, no. 3, pp. 6108-6117, 2009.

[55] T. C. Kuo, H. H. Wu, and J. I. Shieh, "Integration of environmental considerations in quality function deployment by using fuzzy logic," Expert Systems with Applications, vol. 36, no. 3, pp. 7148-7156, 2009.

[56] G. Z. Jia and M. Bai, "An approach for manufacturing strategy development based on fuzzy-QFD," Computers and Industrial Engineering, vol. 60, no. 3, pp. 445-454, 2011.

[57] C. G. Şen and H. Baraçl1, "Fuzzy quality function deployment based methodology for acquiring enterprise software selection requirements," Expert Systems with Applications, vol. 37, no. 4, pp. 3415-3426, 2010.

[58] Y. Yan, H. Liu, Y. Zhang, and Z. Zhou, "A Fuzzy-QFD approach to design decision support system for emergency response of hazardous materials road transportation accidents," in Proceedings of the IEEE International Conference on Automation and Logistics (ICAL '10), pp. 506-510, August 2010.

[59] G. Wang, P. Shi, and C. Wen, "Fuzzy approximation relations on fuzzy $n$-cell number space and their applications in classification," Information Sciences, vol. 181, no. 18, pp. 3846-3860, 2011. 

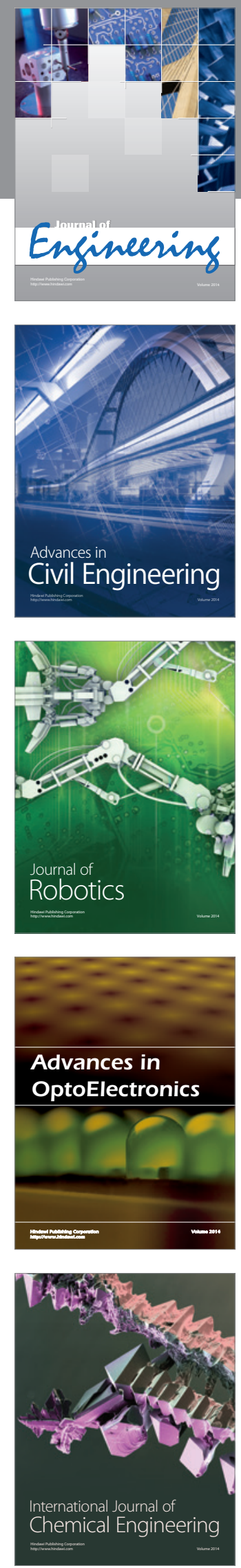

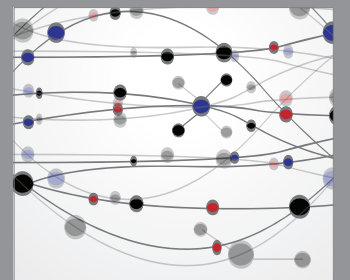

The Scientific World Journal
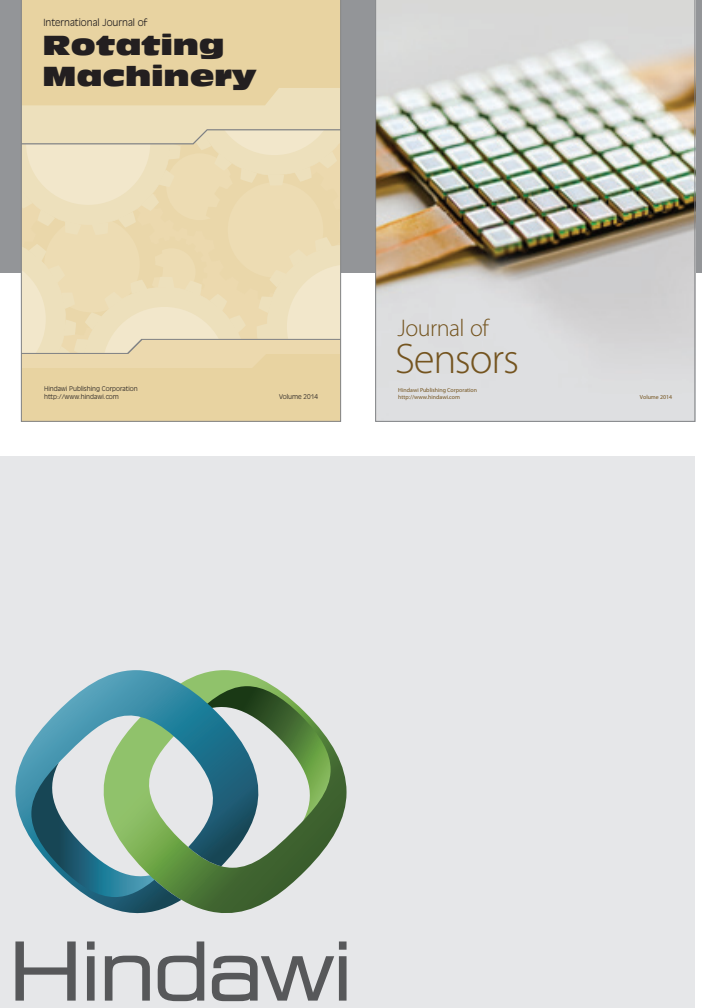

Submit your manuscripts at http://www.hindawi.com
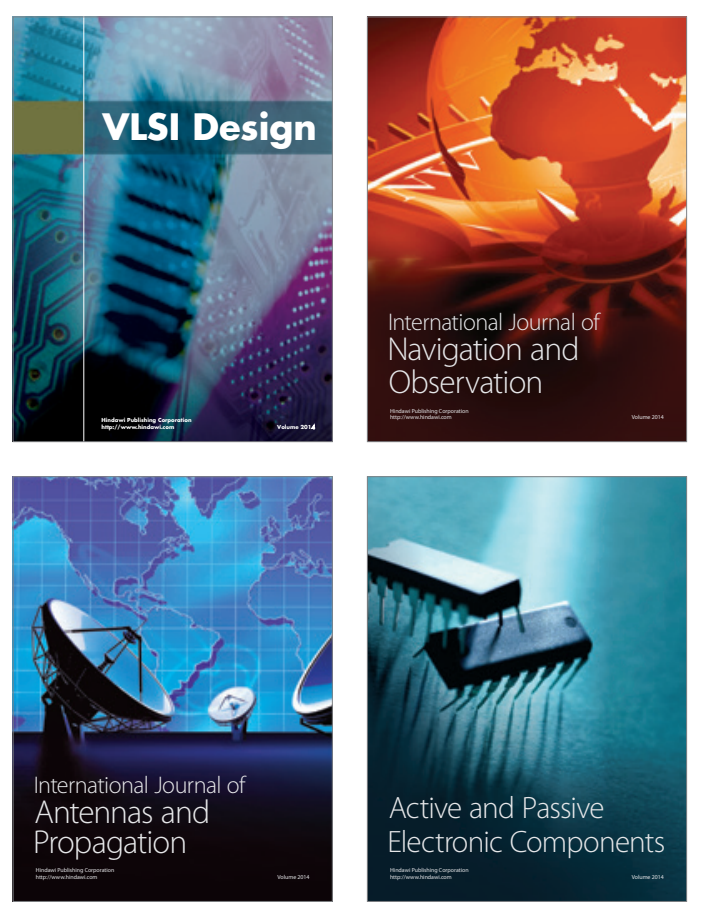
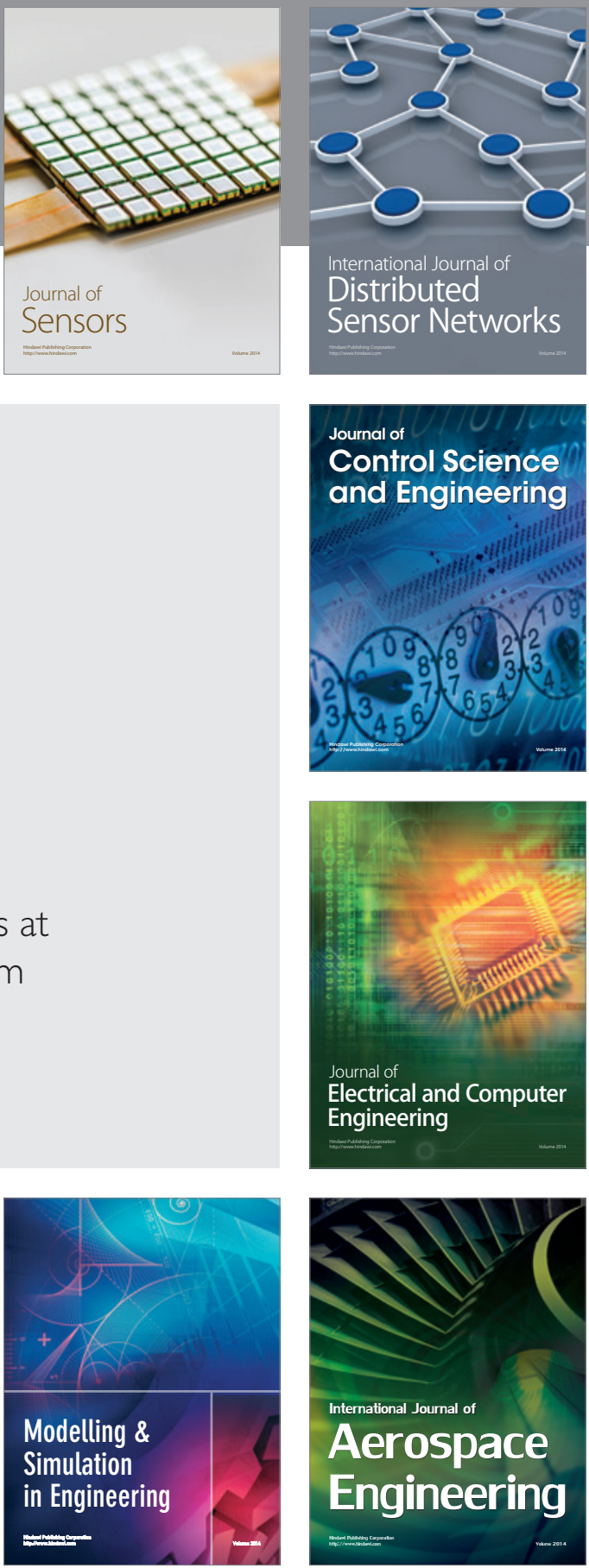

Journal of

Control Science

and Engineering
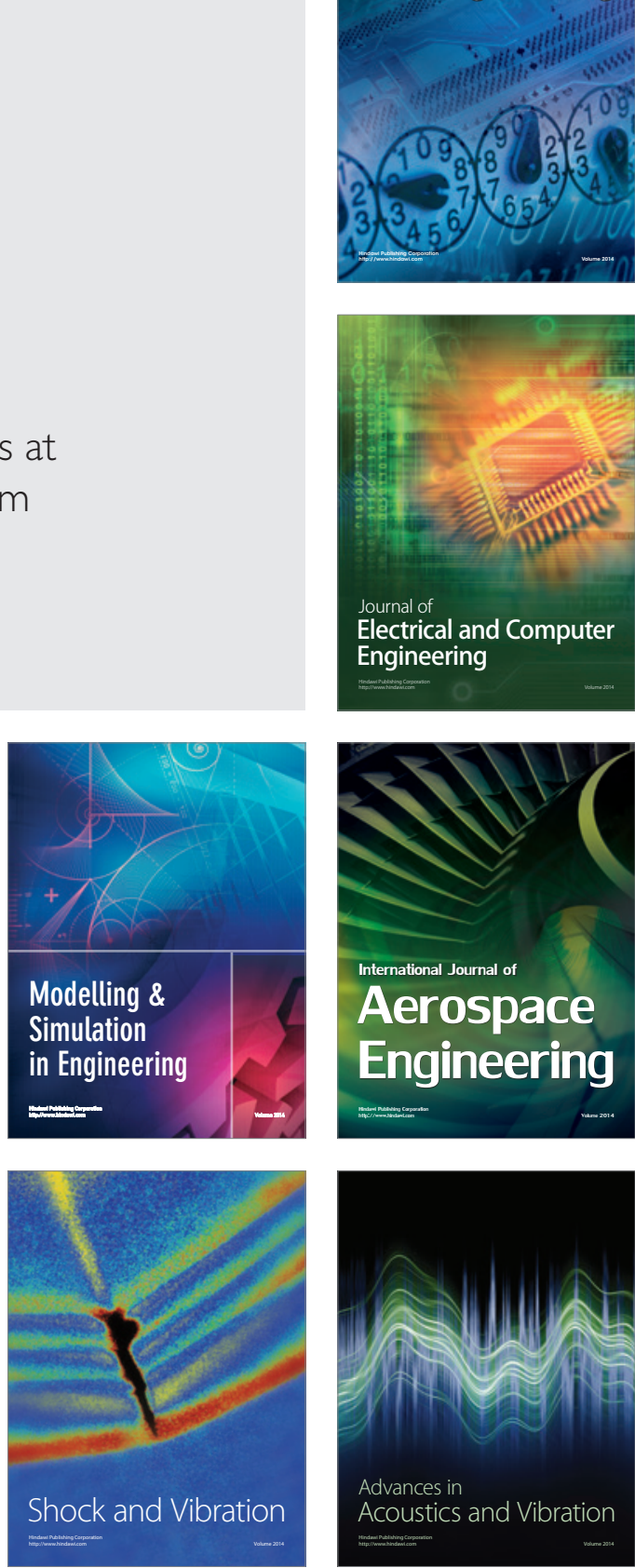